\title{
Difference in Luxury Purchasing Motivation between Chinese and British
}

\author{
Li-Hua WANG ${ }^{1, a,{ }^{*}}$, Qian ZHAO ${ }^{2, b}$ \\ ${ }^{1}$ School of Economics, Hebei University (071002) No.180 Wusidong Road. Baoding City, Hebei \\ Province, P.R.C \\ ${ }^{2}$ De Montfort University, U.K. \\ aolica_w@163.com, ${ }^{\mathrm{b} m a o h u h u q @ y e a h . n e t ~}$ \\ ${ }^{*}$ Corresponding author
}

Keywords: Purchasing Motivations, Personal Motivation, Social Motivation.

\begin{abstract}
This research aims to find out the purchasing motivation of luxury in China and Britain, and the difference between them. Questionnaire for young people was used in this research to get the basic data in the two markets, and found that investment and reference group are new workable motivations in the two markets. This research found that British consumers have paid more attention to some social motivation, while Chinese pay more attention to some personal motivation, which is different with the former reviews.
\end{abstract}

\section{Introduction}

China and Britain both play important role in the global luxury market. China is an emerging luxury market, but having been the largest consumption country while Britain is one of the main traditional markets. Besides, China is an oriental country and Britain is a western country, these two countries have different culture back, social model and income level, these may lead to different purchasing motivation and result in different selection in the two markets. So this research aims to find out the purchasing motivation of luxury in China and Britain, and the difference between them.

There are many experts have researched the issues of luxury consumption motivation. In the early study, gaining respect or winning a higher social status were viewed as the important factors leading to the luxury consumption ${ }^{[1]}$. Leibenstein argued that bandwagon effect should affect the selection of many people ${ }^{[2]}$. Vickers thought the nature of the luxury is the symbol of personal identity, and raised the model of value of symbol. He pointed that compared with the ordinary goods, the value of symbol of the luxury is an important factor influencing the motivation of customers ${ }^{[3]}$. In process of studying the consumption, the idea about the luxury purchasing motivation became mature in the west. And more experts agree that the motivation of the luxury in the west nations prefer to individual-orientated motivation like self-pleasure, self-gift giving, inner-self performance and quality assurance. ${ }^{[4,5]}$

But the idea above is based on western market analyzes, and not suitable for Chinese market completely, which is an emerging luxury market after all. On the other hand, different culture may lead to different purchasing motivation ${ }^{[6]}$. As an eastern country with a long history, Chinese has culture back different from British, so Chinese should have different purchasing motivation. According to some Chinese experts, both social motivation and personal motivation can explain part of the Chinese purchasing behavior, but social motivation play more role than personal ones. ${ }^{[7,8]}$

There are few scholars analyzing the luxury consumption motivations of customers both in the east and west. Ho (1977), Tsai (2005) researched the difference between western and eastern countries and concluded that western consumers prefer to personal motivations and eastern consumers prefer to social motivations ${ }^{[9,10]}$. This research should test this view.

\section{Data Collection}

Questionnaire has been used in this research to find what the younger in China and Britain are thinking about luxury. The questionnaire was developed with reference to the research in Impact of 
personal orientation on Luxury brand purchase value: An International Investigation (Tsai, 2005) and The Attitudes underlying Preferences of Young Urban Educated Polish Consumers Towards Products Made In Western Countries. (Marcoux\&Filiatrault\&Cheron,1997). In this questionnaire, Likert Scale that is five-point scale (from strongly disagree to strongly agree) was used. After in-depth interviews and pre-tested, the final versions of the questionnaire was made including 25 items to test the difference of the two nations in 8 motivations which are snob, conspicuous, gifts, reference group, impulse, quality, investment, self-gift giving, of which the former four motivations are social motivations and the later four are personal motivations.

The sample of the study is a non-probabilistic convenience sample. The respondents were asked to fill the online questionnaire. In order to avoid the misunderstanding caused by translation, we prefer to use the English version. In China, 425 copies of questionnaire come back. Among them, 371 copies are valid. $43.9 \%$ of the respondents are males. Respondents are divided into two age groups: the first group (between 20 and 25), representing 54.0\% of the sample, and the second group (between 26 and 30 ), accounting for $46.0 \%$ of the sample. The majority of the respondents $(73.4 \%)$ have an average income below $3000 \mathrm{RMB}$ per month. This is because the sample is the young people and most of them are still students, about $61 \%$ is the student in college or university. Therefore, the majority of the respondents have limited income level. In UK, 284 copies are valid. 54\% of the respondents are males. Respondents are divided into two age groups: the first group (between 20 and25), representing $38.0 \%$ of the sample, and the second group (between 26 and 30), constituting $62.0 \%$ of the sample. In Britain, the salary question was not mentioned, for the question was an important privacy in Britain. But in UK, many respondents have graduated from colleges which have two years studying time. So the average income in Britain should be higher than in China.

The samples surveyed aimed at the young people (aged from 20 to 30) in two countries for three main reasons. Firstly, the samples are relatively homogeneous in terms of demographics, social background, and education. The data collected have strong comparability. Secondly, compared with old people, young people are more able to read and speak English, which will reduce the misunderstanding caused by translating. Finally, according to the experts' suggestion, the luxury consumer is becoming younger, so young people are likely to be actual or potential customers of luxury products in the future. They represent the future luxury consumption trend.

\section{Finding and Discussion}

A questionnaire including 25 items was made in China and Britain to test the luxury purchasing motivations in the two nations. Here there are 8 motivations were considered, they are snob, conspicuous, gifts, reference group, impulse, quality, investment and self-gift giving. These motivations should be analysis separately on the basis of calculating to the sample data.

\section{Snob}

The consumers in both countries pay great attention to the motivation of snob, the mean score got from questionnaire is 3.04 in China greater than that of Britain which is 2.55. That is Chinese consumer play more attend on snob than British. But the snob in two markets is different. For the item "People's impressions on me have changed after my use of luxury goods", there are 5.54\% of responders extremely agree in China while only $2.53 \%$ in Britain. Other items have similar situation with this item. The reason is that the snob motivation occurs in two circumstances. The first is "when a new prestige product is launched, the snob will adopt the product first to take advantage of the limited number of consumers at that moment" [11], the second is "snob effect is in evidence when status sensitive consumers come to reject a particular product as and when it is seen to be consumed by the general mass of people" ${ }^{[12]}$.In Britain market the snob motivation often occurs in the second circumstance. The consumers acquire the status through being different from others. On the contrary, snob motivation mainly occurs in the first circumstance in Chinese market, and the status needs to be accepted by the public. The different manifestations of this motivation in different nation should be noticed. 


\section{Conspicuous}

There are three items for the motivation of conspicuous. The common view believes this motivation is more suitable for Chinese than British. But this research found that British customers got a higher average score than that of Chinese--British got 2.92 while Chinese got 2.82. According to the interview to the experts, the British young people are playing more attentions to the conspicuous motivation now. And this survey is focus on the views of young in the two nations. But this result explained that the motivations of Chinese customers are becoming mature. Of course, for the young group, the reason of occurring conspicuous motivation should be noticed. It is very important in both two markets.

\section{Gifts}

Agree with the common view, Chinese play higher attend on gifts motivation than British (China is 2.22 and British is 1.92). But this motivation is not so important compare with other motivations when Chinese want to buy luxury (other motivations got more scores except investment). Because the purchasing power of young people in Chinese market is relative weak compared with elder consumers, young people could not afford luxury gifts. Even if young people want to use luxury products as gifts, the high cost prevents their gifting behaviors. Considering the previous research results, the importance of this motivation will grows together with the economic power of China.

\section{Impulse}

For the item "The purchase behavior of friends and relatives would influence me.", there are $40.59 \%$ Chinese agree this view, of which $6.64 \%$ extremely agree, but only $20.95 \%$ in Britain is agree with it and nobody extremely agree. It is similar for the item "I buy a lot of luxury goods, but I seldom use them", there are $12.18 \%$ agree and $4.43 \%$ extremely agree in China while $3.18 \%$ agree and $0 \%$ extremely agree in Britain. This explained that Chinese consumers are more non-rationality than Britain, and they are easier to be influenced by others, and more impulse. So although the Chinese is becoming mature, there is a big gap with the world, after all China is an emerging market. And so, the luxury companies should understand the view of Chinese and make a suitable plan for them.

\section{Quality and Hedonic}

As common views, British consumers will place a greater importance on the pursuit of high quality luxury goods. But in fact this research found that it is Chinese who placed the quality on a more important role. In fact, Chinese consumers combine the Quality and Hedonic motivations. In some ways, quality is positively correlated with the hedonic feeling. Better quality always related with better functions. Chinese luxury market is at the beginning stage. The luxury brands focus on the promotion of their superb quality as the advertising strategy when enter into Chinese market .For example, they emphasize the material and the manual production process. So this motivation becomes the most important one in Chinese consumers' mind. More than $60 \%$ respondents accept this motivation. The Chinese consumers are just getting familiar with the luxury products, so at this stage, they call only accept the tangible aspects of the products. They still need more time to accept the intangible aspects, such as connotation, and understand the representative meaning behind the products.

\section{Self-Gift Giving}

According to the information from literature and experts interviews, the idea that western consumers prefer to buy luxury for self while Chinese consumer buy for others. But the result of this motivation is a bit amazing. The mean score of Chinese is 3.61 while British got 2.63. The purchasing power of Chinese consumers is relatively low. Therefore, Chinese consumers will try to enjoy every aspect of luxury products especially service and purchasing experience. On the contrary, British consumers place a greater importance on luxury products' functional and emotional features. Therefore, Chinese consumers pay more emphasis on self-gift giving than British consumers. 


\section{Investment}

At the beginning, the motivation of investment come from the Chinese experts and was found in the process of in-depth interview with Chinese. So, it was thought as a new motivation in the China market, and assumed Chinese have more willingness to buy luxury for this motivation. The in-depth interview find, in China, some consumers purchase luxury goods because of the potential appreciation opportunity rather than the functional or emotional value. The reason is that now China is growing at a high speed, which is $7.7 \%$ in 2013 according to the National Bureau of Statistics of China. Some people begin buying deluxe brands to display their growing wealth; or to increase their properties using all the possible ways. Luxury goods show the possibility of appreciation because of rareness and exclusiveness. So the investment became a new motivation, especially for Chinese.

But there is a higher mean in Britain indeed. For the item "Purchasing luxury goods is an investment", there is $13.23 \%$ people agree, $4.95 \%$ extremely agree in Britain, while $9.23 \%, 2.95 \%$ respectively in China. In fact, investment is also related with consumers' purchasing power. British consumers' purchasing power is higher than Chinese consumers. Therefore, more people can afford the investment on luxury products. British are the cradle of many luxury brands. British consumers are familiar with luxury culture. So in fact, in Britain, investment to the luxury is not a new phenomenon, though there is no the relatively theory promoted it. The knowledge let British consumers have a better understanding about investment on luxury products than Chinese consumers. Otherwise, the responders of this research is young group, the Chinese young have a limited income, and in this research there is a lot of student responders, they have no income and no the idea to deal with wealth.

\section{Reference Group}

Reference group shows the influence from other people. Just like investment motivation, this motivation comes from Chinese experts and the Chinese interview. So Chinese consumers were expected enjoy it rather than British consumers. In fact, Bearden and Etzel (1982) already proved consumer perceptions of reference group influence on luxury consumption decisions ${ }^{[13]}$. But it was often thought as conformity in western market. This research promotes the difference between reference group and conformity, and uses it as an independent motivation. Because until now, many Chinese consumers have no idea about brand, have no attention to the goods of different brand. They just buy goods with reference to their friends.

But in the research, the result is opposite with the original idea again. The motivation mean of Britain is higher than that of China. In fact, for the two items on the motivation, there are more people agree in Britain than in China. For the item "It is necessary to consume luxury goods under my working environment", there are $25.13 \%$ consumers express agree, and $8.06 \%$ extreme agree in Britain, while $15.12 \%$ and $4.07 \%$ respectively in Chinese; the item "People around me use luxury goods" got the similar result. There are two main reasons, which make reference group a more important motivation in Britain market than in Chinese market. Firstly, Chinese consumers are under strong conformity pressure, so the opinion of reference group may be the same as the social trend. Secondly, luxury products just entered into Chinese market. Only a few people have luxury consumption experience, so it is difficult for reference group to give useful information. The situation is different in Britain. Friends and relatives' advices are good references. Thus, reference group has stronger influence on British consumers than on Chinese consumers.

\section{Summary}

\section{Main Results}

Veblen (1899) is the first person who studied the consumption motivation of luxury, he thought it is "Conspicuous" that promote people to buy luxury; Leibenstein (1950) believed that "Bandwagon" and "Uniqueness" are another two reasons for buying luxury; Mason (1993) emphasis that the status plays an important role in the consumption of luxury; Dubois \& Laurent (1994) promoted the 
personal motivation for the first time, and self-pleasure become the new motivation ${ }^{[14]}$; Vignerson $\&$ Johson (1999) developed the idea of self-concept, and promote the social motivation and personal motivation. In their study, the social motivation includes veblenian, snob, bandwagon; the personal motivation is hedonist \& perfectionist. Tsai (2005) developed the personal motivation, thought self-pleasure, self-gift giving, quality and Congruity with internal self is the main factor influence the personal motivation. Wong (2009) promoted the gift motivation besides other motivations, which had been studied by other experts. Until now, there have been 8 motivations including 4 social motivations and 4 personal motivations. Bearden and Etzel (1982) already proved consumer perceptions of reference group influence on luxury consumption decisions. According to these views, this research planed to examine the motivation of Chinese and British market. In the process of survey, investment and reference group were found, and other motivations were adjusted with reference to the Chinese market and British market. At last, the consumption motivations in this research included snob/status, conspicuous/veblen, impulse/conformity, quality/Hedollic, investment, reference group, gifts, self-gift giving, of which investment and reference group are new motivations in the two markets, impulse is new in Chinese market.

This research studied not only the motivations but also the difference between Chinese and British. Ho (1977) thought the "face consumption" play an important role in the purchasing. Tsai (2005) thought the self-concept can be divided into independent self-concept which emphasis on self-pleasure and Congruity with internal self and associated self-concept which emphasis on the personal statue or snob. And the eastern consumers consume with idea of associated self-concept, western consumers purchasing according to independent self-concept. Combined with these views, this research assumed Chinese consumers prefer to social motivations while British consumers prefer to personal motivations. But the finding is different. This research found that the differences of the motivations between the two nations are significant in four aspects: Snob/Status, Impulse/Conformity, Quality/Hedonic, and Reference Group. In other motivations, the differences are not so obvious. Compare with Chinese, British consumers have pay more attention to the motivation of investment and reference group, which are social motivation, while Chinese pay more attention to the quality motivation, which is personal motivation.

\section{Managerial implications}

According to the finding, this research promoted some implications for the luxury companies. Firstly, this research found that personal motivations are becoming more important than before in Chinese market. This is different from the previous researches which believe the main motivations are social motivations in China. So the conclusion can be get that luxury consumption motivations are changing from social motivations to personal motivations in Chinese market. Especially the young consumers pay more attention to the personal aspects of the luxury products, and they should become the important consumers in near future. So, this research suggests that luxury companies should emphasize the individuality of their goods in the production and strengthen them in the marketing.

Secondly, this research found that some motivations could be affected by other factors, such as cultural background. For example, influenced by the traditional cultural, Chinese consumers pay more attention to the relationship with other people. So the social motivation is more significant in China than in Britain. But this cultural background plays a role not only in the social motivation but also in the personal motivation. So when the personal motivations appear in China, they are affected by the social motivations to some extent. So, the personal motivations in Chinese market have different meanings from western markets. For example, this paper gave the different meaning of hedonic motivation with other research for its different understanding in Chinese market. So, luxury companies should understand the history and cultural background, then analyze the purchasing motivation under this background before they want to enter into a new market.

Thirdly, some motivations are valid motivations for a long time, such as Conspicuous and Snob. In both Chinese market and British market, they have been important in a very long time and should be significant in future. And in Chinese markets, as the newly luxury market, snob is more important 
than in Britain market. So, luxury companies should make a suitable price to explain their goods can give the consumers snob.

Finally, Chinese luxury market is a fast growing market and its growing speed is much faster than western mature markets. The motivations in Chinese market may be change with its growing. So, luxury companies should make market survey regularly and modify the marketing plan according the market in order to have a fast reaction ability to catch the market trends.

\section{Research Limitations}

For some reasons expressed earlier, this research made the sample from people aged from 20 to 30 years old. In fact, the young people have limited purchasing power, especially in China, many responders are students. Although some of them can get some income, but the wealth of themselves cannot afford to the luxury. So many of them have no experience to buy luxury independent even some people are enjoying luxury getting from others as gifts. So to some extent, the survey result cannot reflect the real situation in China.

Secondly, the questionnaire was issued on line, so Chinese responders maybe come from any city of China. But at present, the income gap of Chinese people in different city is very big; people come from different income level must have the different idea on luxury. This may affect the reliability of the result.

Thirdly, the object of this research is all kinds of luxury brand accepted by global market. Some experts have suggested that if the research aims at some kind of the luxury, for example handbag, the research may have a better target, and have a better result.

\section{References}

[1] Veblen, B. Thorstein, The Theory of the Leisure Class: An Economic Study in the Evolution of Institutions, Macmillan, New York, 1899, pp. 57-59

[2] H. Leibenstein, Bandwagon, snob, and Veblen effects in the theory of consumer demand, Quarterly Journal of Economics, Vol. 64(1950) 183-207.

[3] S.J. Vickers, F. Renand, The Marketing of Luxury Goods: An Exploratory Study - three conceptual dimensions, The Marketing Review, volume 3. (2003) 459-478.

[4] Danziger, N. Pamela, Let them eat cake: Marketing Luxury to the masses-as well as the classes, Dearborn Trade Publishing, New York, 2005, pp. 75-78.

[5] Tsai Shu-pei, Impact of personal orientation on luxury-brand purchase value-An international investigation, International Journal of Marketing Research, 47 (2005) 429-454.

[6] Virginie de Barnier, Irina Rodina, Pierre Valette-Florence, which luxury perceptions affect most consumer purchase behavior?A cross cultural exploratory study in France, Russia and the United Kingdom. Working Paper. University Pierre Mendes-Franceof Grenoble. (2005)

[7] Xiaohui Zhu, An Empirical Research on Luxury Consumption Motives of Chinese Consumers, Business Economics and Administration, 3 (2006) 42-48

[8] M.M.Gao, New Luxury Consumption Motivation of the Middle Class, Commercial Times, 12 (2009) 24-35

[9] Ho DYF, On the Concept of Face, American Journal of Sociology, 81 (1977)867-884.

[10] Tsai Shu-pei, Impact of personal orientation on luxury-brand purchase value-An international investigation, International Journal of Marketing Research, 47 (2005) 429-454.

[11] Vigneron, Johnson, A Review and a Conceptual Framework of Prestige-Seeldng Consumer Behavior, Academy of Marketing Science Review, 3(1999)237-261. 
[12] Mason, Roger S., Conspicuous Consumption, St. Martin's Press, New York, 1981.

[13] Bearden , Wlliam O. and Michael J. Etzel, Reference Group Influence on Product and Brand Purchase Decisions,Journal of Consumer Research. 9(1982)183-184

[14] Dubois, Bernard \&Laurent, Gilles, Attitudes Toward the Concept of Luxury: An Exploratory Analysis, Asia-Pacific Advances in Consumer Research, Siew Meng Leong and Joseph A. Cote(eds. ), Singapore, (1994) 273-278. 